\title{
Interleukin-33 in human gliomas: Expression and prognostic significance
}

\author{
DOROTHEE GRAMATZKI $^{1}$, KARL FREI $^{2}$, GIERI CATHOMAS ${ }^{3}$, HOLGER MOCH $^{4}$, \\ MICHAEL WELLER $^{1,5}$ and KIRSTEN DIANA MERTZ ${ }^{3,4}$ \\ ${ }^{1}$ Laboratory for Molecular Neuro-Oncology, Department of Neurology; \\ ${ }^{2}$ Department of Neurosurgery, University Hospital Zurich, 8091 Zurich; ${ }^{3}$ Institute of Pathology Liestal, \\ Cantonal Hospital Baselland, 4410 Liestal; ${ }^{4}$ Department of Pathology, Institute of Surgical Pathology, \\ University Hospital Zurich; ${ }^{5}$ Neuroscience Center Zurich, University of Zurich, 8091 Zurich, Switzerland
}

Received August 8, 2015; Accepted April 29, 2016

DOI: $10.3892 / \mathrm{ol} .2016 .4626$

\begin{abstract}
Interleukin-33 (IL-33) is a nuclear and pleiotropic cytokine with regard to its cellular sources and its actions. IL-33 is involved in the pathogenesis of brain diseases. Several factors account for the tumorigenicity of human gliomas, including cytokines and their receptors. The present study assessed the expression and prognostic significance of IL-33 in human astroglial brain tumors. Protein levels of IL-33 were determined by immunohistochemistry using a tissue microarray containing 95 human gliomas. mRNA expression data of IL-33, as well as of its receptors, IL-1 receptor-like 1 protein and IL-1 receptor accessory protein (IL1RAcP), were obtained from The Cancer Genome Atlas database. IL-33 protein was expressed heterogeneously in tumor tissue, but was, however, not detected in normal brain tissue. There was no differential IL-33 protein expression by tumor grade, while IL-33 protein expression was associated with inferior survival in patients with recurrent glioblastomas. Interrogations of the TCGA database indicated that mRNA expression of IL-33 and the IL-33 receptors was heterogeneous, and that IL-33 and IL1RAcP mRNA levels were correlated with the tumor grade. Elevated IL-33 mRNA levels were associated with the inferior survival of glioblastoma patients. Therefore, IL-33 may play an important role in the pathogenesis and prognosis of human gliomas.
\end{abstract}

\section{Introduction}

Glioblastoma is the most common primary brain tumor, with an annual incidence of 3.9 cases per 100,000 individuals in

Correspondence to: Dr Dorothee Gramatzki, Laboratory for Molecular Neuro-Oncology, Department of Neurology, University Hospital Zurich, Frauenklinikstrasse 26, 8091 Zurich, Switzerland E-mail: dorothee.gramatzki@usz.ch

Key words: interleukin-33, interleukin-1 receptor-like 1 protein, interleukin-1 receptor accessory protein, glioma, tissue microarray, survival the Canton of Zurich (1) and the most aggressive among all gliomas. The standard of care includes radiotherapy plus concomitant and maintenance temozolomide chemotherapy $(\mathrm{TMZ} / \mathrm{RT} \rightarrow \mathrm{TMZ})(2)$, resulting in a median survival time of 16 months in clinical trial populations (3). Several factors account for the tumorigenicity of gliomas, including mutations in selected genes, the amplification of signaling pathway genes, and the exploitation of surrounding non-transformed brain cells induced to provide molecules essential for glioma growth and invasiveness (4,5). Among these, cytokines and their receptors have received significant attention $(6,7)$. For instance, interleukin (IL)-1 $\beta$, IL-6 and IL- 8 are expressed by glioma cells and regulate glioma cell survival, migration and invasion $(8,9)$. However, the expression and function of other IL-1 family members, such as IL-33, in human glioma cells have not been addressed in detail.

IL-33 is recognized for its pro-inflammatory role in inflammatory diseases of mucosal tissues, including allergic asthma, inflammatory bowel diseases and eosinophilic esophagitis (10-14), but also in rheumatoid arthritis and sarcoidosis (15). IL-33 signals through a heterodimeric receptor consisting of IL-1 receptor-like 1 protein (IL1RL1) and IL-1 receptor accessory protein (IL1RAcP). Binding of IL-33 to the receptor activates nuclear factor- $\mathrm{K} \mathrm{B}$ and mitogen-activated protein kinases, in a myeloid differentiation primary response gene 88-dependent manner (16-18).

IL-33 is predominantly and constitutively found in thenucleus of endothelial or epithelial cells of barrier tissues (17,19-21). It mediates the recruitment and activation of immune cells such as mast cells, monocytes, eosinophils, neutrophils, dendritic cells and lymphocyte subsets $(16,22)$. IL-33 can also exert multiple effects on non-immune cells (19-21). Beyond the extracellular receptor-mediated function of IL-33, these effects also appear to be receptor-independent. In this case, IL-33 acts as an intracellular repressor of transcription $(12,20,21,23,24)$.

The role of IL-33 in the human brain is not well known. IL-33 levels were found to be overexpressed in the brain of patients with Alzheimer's disease (25) and multiple sclerosis (26). In the central nervous system (CNS) of mice, IL-33 is constitutively expressed by astrocytes and endothelial cells $(17,27)$, and it can be induced in astrocytes in response 
to inflammatory and necrotic stimuli (28). Since growing evidence indicates that IL-33 plays a role in the maintenance and homeostasis of astrocytes (27-30), it may also contribute to the development and progression of tumors derived from astrocytes. The function of IL-33 in human cancer has remained controversial, but elevated serum levels of IL-33 have been reported in malignancies such as gastric cancer, hepatocellular carcinoma and non-small cell lung cancer (31-33). Recently, it was shown that growth rate and colony formation of tumorigenic $\mathrm{C} 6$ rat glioma cells were attenuated by the inhibition of IL-33 gene expression and that IL-33 induced migration in these cells (34). In the present study, the expression and prognostic significance of IL-33 in gliomas was investigated.

\section{Materials and methods}

Patients. In accordance with the Institutional Review Board, and following the retrieval of informed consent, the surgical specimens and clinical records were retrieved from 95 patients who underwent brain tumor resection between January 2000 and December 2009 at the Department of Neurosurgery, University Hospital Zurich (Zurich, Switzerland). In total, 10 astrocytomas of World Health Organization (WHO) grade I (AI), 14 astrocytomas of WHO grade II (AII), 23 anaplastic astrocytomas (astrocytomas of WHO grade III; AAIII) and 48 glioblastomas were analyzed. The group of glioblastoma patients included 26 newly diagnosed patients and 22 patients with recurrent tumors. In 1 patient, primary and recurrent tumor specimens were obtained. All tumors were classified and graded according to the WHO classification of tumors of the central nervous system (35). Tissues of 4 patients, not diagnosed with brain tumors, were retrieved during autopsy and used as normal brain controls.

Immunohistochemistry. Immunohistochemistry was performed on a tissue microarray (TMA) with archival formalin-fixed $4-\mu \mathrm{m}$ thick sections on SuperFrost slides (Menzel-Glaser, Braunschweig, Germany). Deparaffinized, rehydrated sections were preincubated on the BondMax system (Leica, Mannheim, Germany) in Bond Epitope Retrieval Solution 2 (pH 9.0) for $30 \mathrm{~min}$ at $95^{\circ} \mathrm{C}$ and then stained for IL-33 using goat anti-human IL-33 immunoglobulin (Ig)G (catalog no. AF3625; R\&D Systems Inc., Minneapolis, MN, USA) at a dilution of 1:400. The specificity of IL-33 staining was confirmed by negative staining with isotype-matched IgG (catalog no. AB-108-C; R\&D Systems Inc.). The immunostaining results were assessed as the percentage of IL-33-positive (IL-33+) cells (nuclear staining) (21). Scoring was performed by one scientist in a blinded manner.

Interrogations of The Cancer Genome Atlas (TCGA) database. Microarray and outcome data were obtained from the glioblastoma data set of the TGCA network available on December 11, 2014 (http://cancergenome.nih.gov/) (36). The gene expression data in this database were obtained using Affymetrix array. The query was based on the reporter with the highest mean geometric intensity for the target gene. The Affymetrix probesets used in the TCGA database were 209821_at for IL-33, 205227_at for IL1RAcP and 234066_at for IL1RL1. The TCGA database used for this study contains data of 276 gliomas of different histologies and 8 control samples (37). Survival analysis within the glioblastoma data set of the TCGA database was performed using the Kaplan-Meier analysis module of the R2 microarray analysis and visualization platform (http://r2.amc.nl). The cut-off to segregate glioblastoma patients into two groups with high or low expression of the target gene was defined by the average expression level of the target gene.

Statistics. Progression-free survival (PFS), overall survival (OS) and post-recurrence survival (PRS) curves were estimated by the Kaplan-Meier method and compared with the two-sided log-rank test. PFS time was calculated from the date of surgery to the date of recurrence. OS time was measured from the date of first surgery to the date of mortality. PRS time was measured from the date of the surgery in which the tissue was obtained to the date of mortality. Patients without confirmed mortality were censored for OS and PRS at the last follow-up visit. Patients without documented progression were censored at the last follow-up visit for PFS, PRS and OS. The Kruskal-Wallis test (one-way analysis of variance for non-parametric values), in combination with Dunn's multiple comparison test, was used to compare protein or mRNA levels within groups. Survival-associated analyses were calculated with the log-rank test. All statistical analyses were performed using Prism 5 (GraphPad Software Inc., La Jolla, CA, USA). P $<0.05$ was considered to indicate a statistically significant difference.

\section{Results}

Patient and tumor characteristics. Tissue sections of 95 patients from a single center with newly diagnosed or recurrent glioma were analyzed, and the patient characteristics are presented in Table I. Glioblastoma patients were older (median age, 56.5 years) than patients diagnosed with WHO grade I (median age, 20 years), WHO grade II (median age, 37.5 years) or WHO grade III (median age, 41 years) tumors. In the group of WHO grade II-IV patients, males were more often affected than females. The median OS time in the group of glioblastoma patients (14 months) was worse than that for patients diagnosed with WHO grade III gliomas (41 months). The median OS time for patients with WHO grade II was 14.3 years, whereas the median survival time for patients diagnosed with WHO grade I was 22 years. The median OS time in the group of newly diagnosed glioblastoma patients was 10 months, while in the group of recurrent glioblastoma patients, the median OS time was 22 months. The PRS time for recurrent glioblastoma patients was 5 months.

IL-33 is expressed in human gliomas and is associated with inferior survival in patients with recurrent glioblastoma. Protein levels of IL-33 were assessed by immunohistochemistry using a TMA (Fig. 1A and B). The TMA cores of normal brain tissue showed a number of IL-33-negative (IL-33') neuronal cells and only very few, scattered, normal astrocytes with weak nuclear IL-33 expression. When captured on the TMA, infiltrating immune cells were negative. The IL-33 mean labeling indexes in the tumor cells were $13.3 \%$ [range, $0-65 \%$; 95\% confidence interval (CI), 2.2-28.7) for AI, $15.4 \%$ (range 0-70\%; 95\% CI, 2.6-28.1) for AII, 19.7\% (range, 0-60\%; 95\% CI, 9.2-30.2) for AAIII and $21.7 \%$ (range, $0-92.5 \%$; 
Table I. Patient characteristics.

\begin{tabular}{|c|c|c|c|c|c|c|}
\hline \multirow[b]{2}{*}{ Characteristic } & \multicolumn{6}{|c|}{ WHO grade } \\
\hline & $\begin{array}{c}\mathrm{I} \\
(\mathrm{n}=10)\end{array}$ & $\begin{array}{c}\text { II } \\
(n=14)\end{array}$ & $\begin{array}{c}\text { III } \\
(n=23)\end{array}$ & $\begin{array}{c}\mathrm{IV} \\
(\mathrm{n}=48)\end{array}$ & $\begin{array}{l}\text { IV nd } \\
(\mathrm{n}=26)\end{array}$ & $\begin{array}{l}\text { IV rec } \\
(\mathrm{n}=22)\end{array}$ \\
\hline \multicolumn{7}{|c|}{ Age at diagnosis, years } \\
\hline Median & 20.0 & 37.5 & 41.0 & 56.5 & 58.5 & 53.0 \\
\hline Range & $1-29$ & $23-69$ & $24-75$ & $18-80$ & $21-80$ & $18-79$ \\
\hline \multicolumn{7}{|l|}{ Gender, $\mathrm{n}$} \\
\hline Female & 5 & 4 & 10 & 15 & 10 & 5 \\
\hline Male & 5 & 10 & 13 & 33 & 16 & 17 \\
\hline \multicolumn{7}{|c|}{ Survival, months (events) } \\
\hline $\begin{array}{c}\text { Median OS } \\
(95 \% \mathrm{CI})\end{array}$ & $264(2)$ & $172(3)$ & $\begin{array}{c}41(12) \\
-\end{array}$ & $\begin{array}{l}14(39) \\
(2.9-7)\end{array}$ & $\begin{array}{l}10(21) \\
(2.9-6)\end{array}$ & $\begin{array}{c}22(18) \\
(3-14.2)\end{array}$ \\
\hline $\begin{array}{l}\text { Median PRS } \\
(95 \% \mathrm{CI})\end{array}$ & n. a. & n. a. & n. a. & n. a. & n. a. & $\begin{array}{c}5(18) \\
(4.0-10.1)\end{array}$ \\
\hline
\end{tabular}

WHO grades I-IV correspond with AI, AII, AAIII and glioblastoma tumors, respectively. WHO, World Health Organization; events, number of patients with confirmed death; OS, overall survival; PRS, post-recurrence survival; CI, confidence interval; nd, newly diagnosed; rec, recurrent; n.a., not applicable.

95\% CI, 13.1-30.3) for glioblastoma (Fig. 1B). Thus, the highest mean IL-33 labeling indexes were observed in glioblastoma, but these did not differ significantly from gliomas of other grades. When newly diagnosed and recurrent tumor samples for glioblastoma patients were analyzed separately, the mean percentages were $19.4 \%$ (range, $0-92.5 \%$; 95\% CI, 8.9-29.9) for newly diagnosed tumors and $24.4 \%$ (range, 0-90\%; 95\% CI, 9.4-39.5) for recurrent tumors (Fig. 1C). Based on the percentages of the IL-33 labeling indexes, patients were divided into two groups: Negative $(0 \%)$ and positive $(\geq 1 \%)$ for IL-33. The ratios of IL-33 to $\mathrm{IL}-33^{+}$patients per WHO grade were as follows: AI, 50/50; AII, 57/43; AAIII, 57/43; and glioblastoma, 48/52. Nuclear IL-33 was also regularly found in endothelial cells of vessels that were randomly captured on TMA cores of tumor and normal brain tissues (data not shown).

To search for an association between IL-33 labeling indexes and survival, patients with glioblastoma were divided into two groups, defined as positive or negative for this cytokine. Patient characteristics of IL-33- or IL-33+ ${ }^{+}$patients separated for newly diagnosed or recurrent tumors are summarized in Table II. In the group of newly diagnosed glioblastomas $(n=26)$, the median age was 63 years in the IL-33- group and 57 years in the IL- $33^{+}$group. There was a male predominance in the group of IL-33- patients. The pre-operative Karnofsky performance score (KPS) was similar in the two groups. Treatment regimes in the groups differed: While the majority of IL-33- patients had received TMZ/RT $\rightarrow$ TMZ (66.7\%), the majority of $\mathrm{IL}^{-33} 3^{+}$patients had received RT only $(42.9 \%)$ or TMZ/RT (21.4\%), due to early tumor progression (Table II). The median PFS time was 6 months for the IL-33- patients and 3 months for the IL-33+ patients $(\mathrm{P}=0.709)$ (Fig. 1D). The OS time was 13 months for the IL-33- patients and 9 months for the $\mathrm{IL}-33^{+}$patients $(\mathrm{P}=0.815)$ (Fig. $\left.1 \mathrm{E}\right)$. In the recurrent glioblastoma group $(n=22)$, the median age was 50 years in the IL-33- group and 59 years in the IL- $33^{+}$group. The pre-operative KPS was similar in the two groups. Prior to second surgery, the majority of IL-33- patients had received $\mathrm{TMZ} / \mathrm{RT} \rightarrow \mathrm{TMZ}(27.3 \%)$ or $\mathrm{RT} \rightarrow \mathrm{TMZ}(27.3 \%)$, whereas the group of $\mathrm{IL}-33^{+}$patients received $\mathrm{TMZ} / \mathrm{RT} \rightarrow \mathrm{TMZ}(54.5 \%)$ (Table II). In total, $45.5 \%$ of the recurrent patients in each group, IL-33+ ${ }^{+}$or IL-33- ${ }^{-}$, received TMZ alone as post-surgery treatment at the time of recurrence (Table II). The median PFS time was 13 months for the IL-33-patients and 6 months for the IL-33+ ${ }^{+}$patients $(\mathrm{P}=0.308)$ (Fig. 1D). The median OS time was 34 months for the IL-33- patients and 14 months for the IL-33 ${ }^{+}$patients $(\mathrm{P}=0.045)$ (Fig. $\left.1 \mathrm{E}\right)$. The median PRS time was 10 months for the IL-33- patients and 4 months for the IL-33 ${ }^{+}$ patients $(\mathrm{P}=0.026)$ (Fig. $1 \mathrm{~F})$.

IL-33 expression in human gliomas: An analysis of the TCGA database. Microarray data were acquired from the TCGA database (36) and a glioma population (37), including AI $(n=8)$, AII $(n=24)$, AAIII $(n=85)$ and glioblastoma $(n=159)$ samples selected for validation of IL-33 expression and its prognostic significance. Another 8 normal brain samples were included. The median mRNA expression levels of IL-33 were 6.2 (95\% CI, 5.3-6.9) for normal brain tissues, 6.8 (95\% CI, 5.31-6.85) for AI, 7.3 (95\% CI, 6.5-7.5) for AII, 6.4 (95\% CI, 5.8-6.6) for AAIII and 7.0 (95\% CI, 6.7-7.1) for glioblastoma (Fig. 2A). The median IL-33 mRNA expression levels varied significantly $(\mathrm{P}=0.02)$, but multiple comparisons between each tumor grade did not demonstrate statistically significant results (Fig. 2A).

Next, the IL-33 receptors, IL1RL1 and IL1RAcP, were analyzed. The median mRNA expression levels of IL1RL1 were 6.2 (95\% CI, 5.3-6.9) for normal brain tissues, 6.8 (95\% CI, 5.31-6.85) for AI, 7.3 (95\% CI, 6.5-7.5) for AII, 6.4 (95\% CI, 5.8-6.6) for AAIII and 7.0 (95\% CI, 6.7-7.1) for glioblastoma (Fig. 2B). mRNA levels were not increased or decreased in any of the analyzed groups compared with each 
A
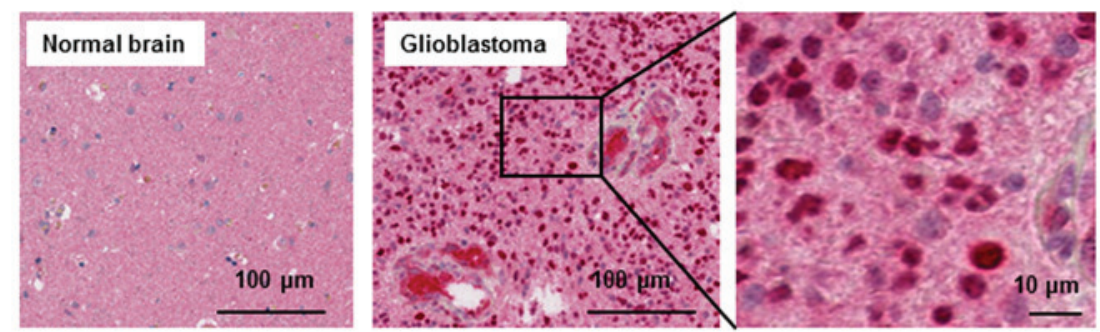

B

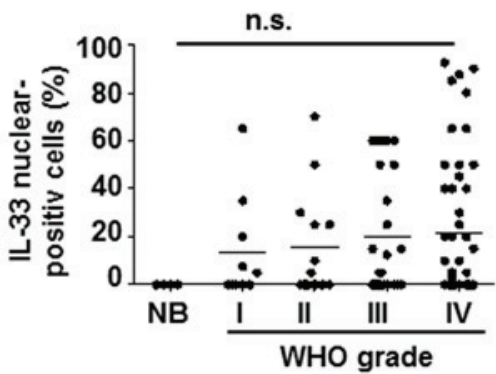

C

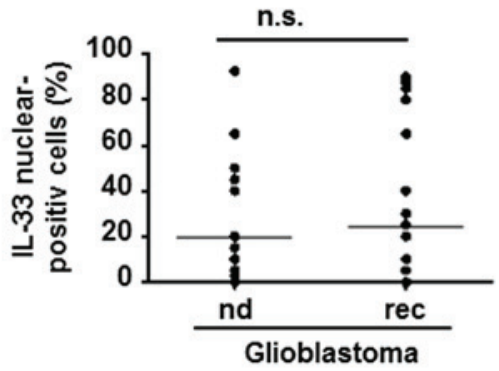

D
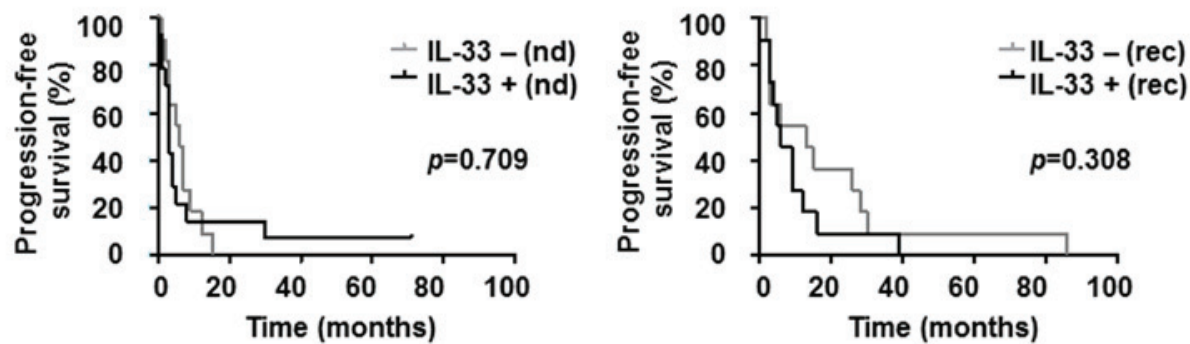

E
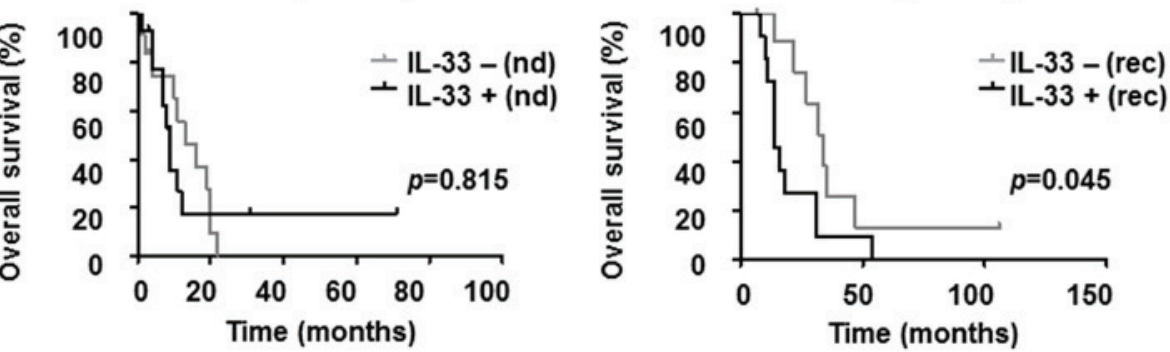

$\mathbf{F}$

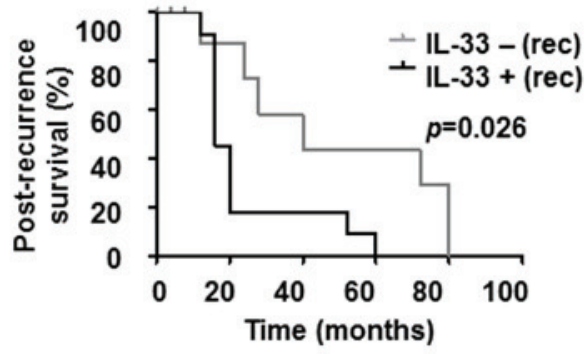

Figure 1. IL-33 protein labeling in human gliomas. (A) Representative tissue sections demonstrating no nuclear staining of IL-33 in normal brain tissues, but strong nuclear staining in glioblastoma. (B) The percentage of IL-33 nuclear-positive cells was assessed by immunohistochemistry of human normal brain tissues (NB), World Health Organization grade I (AI), II (AII) and III astrocytomas (AAIII), and glioblastoma (grade IV astrocytomas) samples. Each tissue sample is indicated by a dot. The black bar marks the mean in each group. (C) The percentage of IL-33 nuclear-positive cells was assessed in nd and rec glioblastomas. (D) Progression-free survival and (E) overall survival are shown in nd (left) and rec (right) patients. (F) Post-recurrence survival data. IL-33 ${ }^{+}$ patients were compared with IL-33- patients ( $\mathrm{P}<0.05$ was considered significant). IL-33, interleukin-33; n.s., not significant; nd, newly diagnosed; rec, reccurrent; IL-33+, IL-33-positive; IL-33-, IL-33-negative.

other. By contrast, the median IL1RAcP mRNA levels were increased in the glioblastoma patients compared with that of the patients diagnosed with AII $(\mathrm{P}<0.01)$ or AAIII $(\mathrm{P}<0.01)$. The median mRNA expression levels of IL1RAcP were 5 (95\% CI, 4.6-5.3) for normal brain tissues, 8.4 (95\% CI, 7.1-8.9) for AI, 5.7 (95\% CI, 5.3-6.4) for AII, 6.6 (95\% CI, 6.4-7.1) for AAIII and 7.9 (95\% CI, 7.6-8) for glioblastoma (Fig. 2C). A correlation in mRNA expression levels was found between
IL-33 and IL1RAcP ( $\mathrm{r}=0.14, \mathrm{P}=0.02)$, but not between IL-33 and IL1RL1 ( $\mathrm{r}=0.08, \mathrm{P}=0.20)$. There were no correlations between the IL-33 receptors ( $\mathrm{r}=-0.04, \mathrm{P}=0.52)$ (Fig. 2D). Finally, microarray and outcome data for glioblastoma were obtained from the TCGA database. Patients were divided into two groups with high or low IL-33 mRNA expression. The cut-off was defined by the average mRNA expression level of the target gene. Patients with higher IL-33 mRNA expression 
Table II. Clinical characteristics, treatment and outcome in human glioblastoma by IL-33 protein labeling indexes.

\begin{tabular}{|c|c|c|c|c|}
\hline \multirow[b]{2}{*}{ Characteristic } & \multicolumn{2}{|c|}{ Newly diagnosed } & \multicolumn{2}{|c|}{ Recurrent } \\
\hline & $\begin{array}{l}\text { IL-33- } \\
(n=12)\end{array}$ & $\begin{array}{l}\mathrm{IL}^{-33^{+}} \\
(\mathrm{n}=14)\end{array}$ & $\begin{array}{l}\text { IL-33- } \\
(\mathrm{n}=11)\end{array}$ & $\begin{array}{l}\mathrm{IL}^{-33^{+}} \\
(\mathrm{n}=11)\end{array}$ \\
\hline \multicolumn{5}{|l|}{ Age, years } \\
\hline Median & 63 & 57 & 50 & 59 \\
\hline Range & $21-77$ & $41-80$ & $21-63$ & $18-79$ \\
\hline \multicolumn{5}{|l|}{ Age groups, n (\%) } \\
\hline$\leq 40$ years & $1(8.3)$ & $0(0.0)$ & $3(27.3)$ & $3(27.3)$ \\
\hline $41-50$ years & $2(16.7)$ & $4(28.6)$ & $3(27.3)$ & 0 \\
\hline $51-60$ years & $3(25.0)$ & $4(28.6)$ & $3(27.3)$ & $4(36.4)$ \\
\hline $61-70$ years & $1(8.3)$ & $3(21.4)$ & $2(18.2)$ & $3(27.3)$ \\
\hline$>70$ years & $5(41.7)$ & $3(21.4)$ & $0(0.0)$ & $1(9.1)$ \\
\hline \multicolumn{5}{|l|}{ Gender, n (\%) } \\
\hline Female & $1(8.3)$ & $9(64.3)$ & $1(9.1)$ & $4(36.4)$ \\
\hline Male & $11(91.7)$ & $5(35.7)$ & $10(90.9)$ & $7(63.6)$ \\
\hline \multicolumn{5}{|l|}{ KPS (pre-operative), n (\%) } \\
\hline $90-100$ & $1(8.3)$ & $1(7.1)$ & $5(45.5)$ & $3(27.3)$ \\
\hline $70-80$ & $8(66.7)$ & $11(78.6)$ & $5(45.5)$ & $7(63.6)$ \\
\hline$<70$ & $3(25.0)$ & $2(14.3)$ & $1(9.1)$ & $1(9.1)$ \\
\hline \multicolumn{5}{|l|}{ Tumor localization, n (\%) } \\
\hline Frontal & $2(16.7)$ & $3(21.4)$ & $1(9.1)$ & $4(36.4)$ \\
\hline Parietal & $0(0.0)$ & $2(14.3)$ & $3(27.3)$ & $0(0.0)$ \\
\hline Temporal & $3(25.0)$ & $7(50.0)$ & $5(45.5)$ & $5(45.5)$ \\
\hline Occipital & $0(0.0)$ & $0(0.0)$ & $0(0.0)$ & $0(0.0)$ \\
\hline Brainstem & $0(0.0)$ & $0(0.0)$ & $0(0.0)$ & $0(0.0)$ \\
\hline Cerebellar & $0(0.0)$ & $0(0.0)$ & $0(0.0)$ & $0(0.0)$ \\
\hline Spinal & $0(0.0)$ & $0(0.0)$ & $0(0.0)$ & $0(0.0)$ \\
\hline Multifocal (>2 regions) & $5(41.7)$ & $2(14.3)$ & $2(18.2)$ & $2(18.2)$ \\
\hline \multicolumn{5}{|l|}{ Surgery, n (\%) } \\
\hline Biopsy & $0(0.0)$ & $0(0.0)$ & $0(0.0)$ & $0(0.0)$ \\
\hline Partial resection & $2(16.7)$ & $2(14.3)$ & $1(9.1)$ & $2(18.2)$ \\
\hline Subtotal resection & $9(75.0)$ & $2(14.3)$ & $3(27.3)$ & $6(54.5)$ \\
\hline Gross total resection & $1(8.3)$ & $10(71.4)$ & $7(63.6)$ & $2(18.2)$ \\
\hline No data & $0(0.0)$ & $0(0.0)$ & $0(0.0)$ & $1(9.1)$ \\
\hline \multicolumn{5}{|l|}{ First-line therapy, n (\%) } \\
\hline No therapy & $2(16.7)$ & $2(14.3)$ & $1(9.1)$ & $2(18.2)$ \\
\hline RT alone & $1(8.3)$ & $6(42.9)$ & $2(18.2)$ & $1(9.1)$ \\
\hline $\mathrm{RT} \rightarrow \mathrm{TMZ}$ & $3(25.0)$ & $1(7.1)$ & $3(27.3)$ & $2(18.2)$ \\
\hline TMZ/RT & $0(0.0)$ & $3(21.4)$ & $2(18.2)$ & $0(0.0)$ \\
\hline $\mathrm{TMZ} / \mathrm{RT} \rightarrow \mathrm{TMZ}$ & $8(66.7)$ & $1(7.1)$ & $3(27.3)$ & $6(54.5)$ \\
\hline TMZ alone & $0(0.0)$ & $1(7.1)$ & $0(0.0)$ & $0(0.0)$ \\
\hline No data & $1(8.3)$ & $0(0.0)$ & $0(0.0)$ & $0(0.0)$ \\
\hline \multicolumn{5}{|l|}{$\begin{array}{l}\text { Post-second or -third surgery } \\
\text { treatment }{ }^{\mathrm{a}}, \mathrm{n}(\%)\end{array}$} \\
\hline No therapy & & & $2(18.2)$ & $1(9.1)$ \\
\hline $\mathrm{TMZ} / \mathrm{RT} \rightarrow \mathrm{TMZ}$ & & & $1(9.1)$ & $1(9.1)$ \\
\hline TMZ alone & & & $5(45.5)$ & $5(45.5)$ \\
\hline Lomustine alone & n. a. & n. a. & $2(18.2)$ & $0(0.0)$ \\
\hline Gefitinib alone & & & $0(0.0)$ & $1(9.1)$ \\
\hline Bevacizumab plus irinotecan & & & $0(0.0)$ & $2(18.2)$ \\
\hline No data & & & $1(9.1)$ & $1(9.1)$ \\
\hline
\end{tabular}


Table II. Continued.

\begin{tabular}{|c|c|c|c|c|}
\hline \multirow[b]{2}{*}{ Characteristic } & \multicolumn{2}{|c|}{ Newly diagnosed } & \multicolumn{2}{|c|}{ Recurrent } \\
\hline & $\begin{array}{l}\text { IL-33- } \\
(n=12)\end{array}$ & $\begin{array}{l}\mathrm{IL}^{-33^{+}} \\
(\mathrm{n}=14)\end{array}$ & $\begin{array}{l}\text { IL-33- } \\
(\mathrm{n}=11)\end{array}$ & $\begin{array}{l}\mathrm{IL}^{-33^{+}} \\
(\mathrm{n}=11)\end{array}$ \\
\hline \multicolumn{5}{|l|}{ Survival } \\
\hline Median follow-up, months & 12 & 7.5 & 27 & 14 \\
\hline $\begin{array}{l}\text { Median PFS, months (events) } \\
(95 \% \text { CI })\end{array}$ & $\begin{array}{c}6(11) \\
(1.9-8.9)\end{array}$ & $\begin{array}{l}3(13) \\
(0.9-5)\end{array}$ & $\begin{array}{r}13(11) \\
(3-27.9)\end{array}$ & $\begin{array}{c}6(11) \\
(3-12)\end{array}$ \\
\hline $\begin{array}{l}\text { Median PRS, months (events) } \\
(95 \% \text { CI })\end{array}$ & n.a. & n.a. & $\begin{array}{c}10(7) \\
(3.9-54.9)\end{array}$ & $\begin{array}{c}4(11) \\
(-)\end{array}$ \\
\hline $\begin{array}{l}\text { Median OS, months (events) } \\
(95 \% \mathrm{CI})\end{array}$ & $\begin{array}{c}13(11) \\
(1.9-19.8)\end{array}$ & $\begin{array}{c}9(10) \\
(3.8-11.9)\end{array}$ & $\begin{array}{c}34(7) \\
(9.9-30.5)\end{array}$ & $\begin{array}{c}14(11) \\
(-)\end{array}$ \\
\hline Alive at last follow up, $\mathrm{n}(\%)$ & $1(8.3)$ & $4(28.6)$ & $4(36.4)$ & $0(0.0)$ \\
\hline
\end{tabular}

${ }^{a}$ Data are reported from the date of the surgery in which the tissue was obtained.IL-33, interleukin-33; TMZ, temozolomide; PFS, progression-free survival; PRS, post-recurrence survival; OS, overall survival; events, number of patients with confirmed progression or death; CI, confidence interval; RT, radiotherapy; -, negative; +, positive; n. a., not applicable; KPS, Karnofsky performance score. TMZ/RT $\rightarrow$ TMZ, radiotherapy plus concomitant and maintenance temozolomide chemotherapy.

A

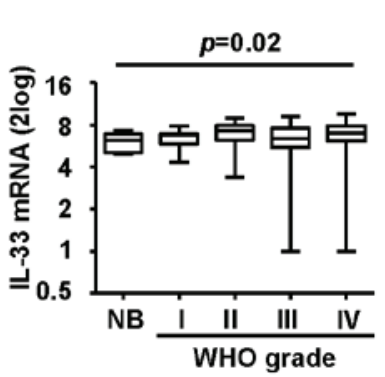

D

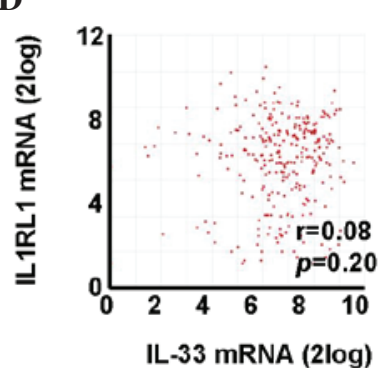

$\mathbf{E}$

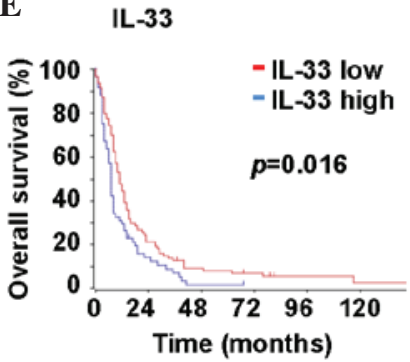

B
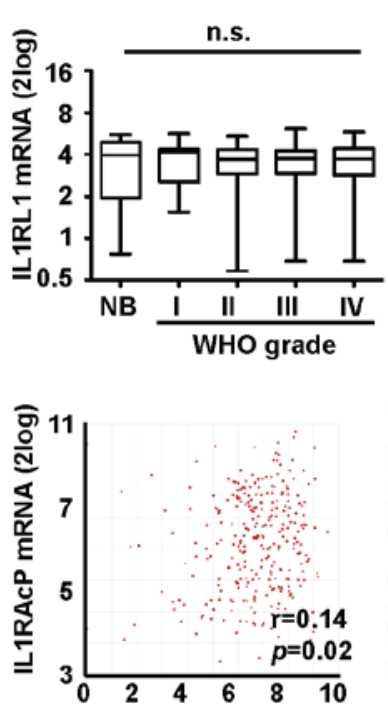

IL-33 mRNA (2log)

IL1RL1

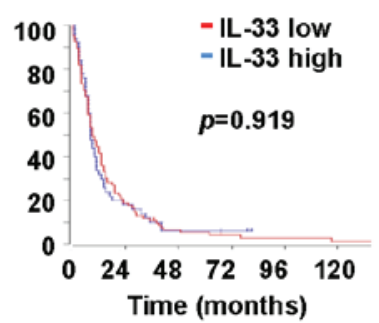

C
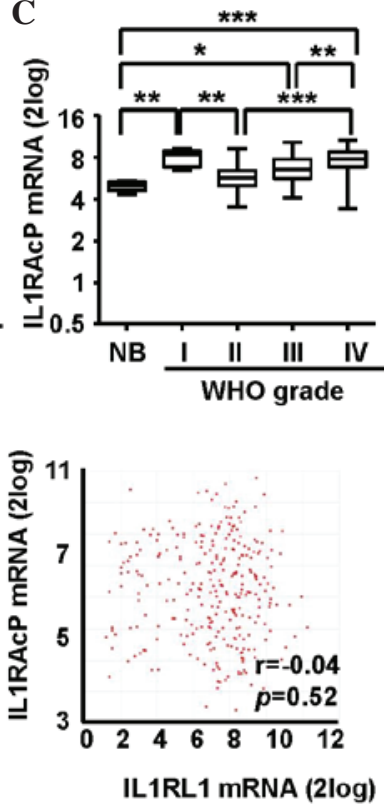

IL1RAcP

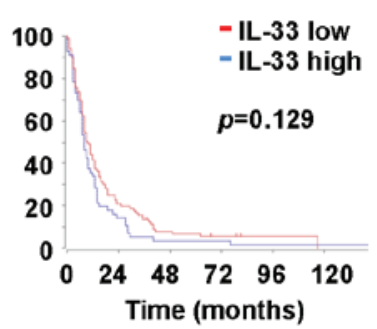

Figure 2. IL-33 mRNA expression in human gliomas: An analysis of The Cancer Genome Atlas (TCGA) network. (A) Interleukin-33 (IL-33), (B) IL-1 receptor-like 1 protein (IL1RL1) and (C) IL-1 receptor accessory protein (IL1RAcP) mRNA expression levels of normal brain (NB), World Health Organization grade I (AI), II (AII) and III astrocytomas (AAIII), and glioblastomas (grade IV astrocytomas) were obtained from the TCGA database. Box plots are shown (median, range). Values are represented in a logarithmic scale. P-values were assessed using the Kruskal Wallis test. (D) Pairwise correlation was assessed among mRNA data of IL-33, IL1R1 and IL1RAcP. Two-tailed Spearman test coefficients (r) and significances (p) are indicated. Values are represented in a logarithmic scale. (E) Kaplan-Meier survival curves of overall survival are shown for the group of glioblastoma patients. Patients were divided into two groups with high (blue line) vs. low (red line) IL-33 mRNA expression. The cut-off was defined by the average mRNA expression level of the target for glioblastoma. Target genes were IL-33, IL1RL1 or IL1RAcP ( $\mathrm{P}<0.05$ was considered significant). ${ }^{*} \mathrm{P}<0.05 ;{ }^{* *} \mathrm{P}<0.01 ;{ }^{* * * *} \mathrm{P}<0.001 ;$ n.s., not significant. 
levels experienced inferior survival $(\mathrm{P}=0.016)$. IL1RL1 and IL1RAcP mRNA expression levels were not associated with survival in the group of glioblastoma patients (Fig. 2E).

\section{Discussion}

Members of the IL-1 family (e.g., IL-1 $\beta$, IL-6 and IL-8) are expressed by glioma cells and modulate survival, migration and invasion (8). IL-33, another IL-1 family member, is a pleiotropic cytokine that may be involved in the pathogenesis of brain diseases (38). IL-33 is a pro-inflammatory mediator activating microglia, and inducing inflammatory cytokines and chemokines, and thus may have neuroprotective or neurotoxic effects depending on tissue conditions. In a previous study, the increased expression of IL-33 contributed to enhanced cell growth of rat glioma cells and the invasion of microglia (34). Moreover, exogenously administrated IL-33 enhanced primary tumor growth and inhibited innate antitumor immunity in a metastatic breast cancer model (39).

The purpose of the present study was to assess IL-33 expression in human astroglial brain tumors and to evaluate its prognostic significance. Normal brain sections were found to be negative for IL-33 protein expression. The high level IL-33 detection in certain astrocytomas suggested a pathogenetic role for this cytokine (Fig. 1B). On the other hand, similar levels of IL-33 across all WHO grades showed IL-33 production to be independent of the grade of malignancy. Furthermore, protein levels of IL-33 were markedly similar among newly diagnosed and recurrent glioblastomas, indicating that treatment in this patient population does not significantly affect its expression (Fig. 1C). IL-33 protein labeling indexes were not associated with PFS in the glioblastoma patients (Fig. 1D). However, in the subgroup of recurrent glioblastoma patients, IL-33 $3^{+}$tumors demonstrated inferior OS and PRS compared with IL-33- tumors (Fig. 1E and F). This could indicate that IL-33 expression may be an important feature for advanced glioblastoma patients. In line with these indications, IL-33 is known to enhance tumor surveillance and antitumor immunity $(40,41)$. Therefore, IL-33 may contribute to tumor progression and antitumor activity, depending on the levels of IL-33 and the microenvironment. The microenvironment of gliomas in situ comprises not only stromal CNS-intrinsic cell types, such as astrocytes and microglial cells, but also inflammatory cells that have infiltrated into the tumor from the circulation, including lymphocytes, macrophages, neutrophils and eosinophils $(42,43)$. Although these infiltrating immune cells may seek to curb tumor growth initially, evidence points to the tumor subsequently affecting the immune cells to allow its growth. Necrosis or inflammation in the CNS causes the release of IL-33, particularly from astrocytes and glioma cells. However, since there is a population of resident mast cells in the CNS $(44,45)$, it would also lead to the secretion of IL-33 by the mast cells. This could have profound effects in glioma progression since IL-33 may then in turn act not only on astrocytes, but also on tumor cells and possibly other CNS glial cells to induce STAT6-responsive genes to complete an important, neural-immune circuit (46).

TCGA interrogation in the present study indicated that the mRNA levels of IL-33, as well as those of IL1RAcP, are upregulated in human glioblastoma (Fig. 2A and C), and that
IL-33 mRNA expression correlates with IL1RAcP mRNA expression (Fig. 2D), suggesting that there may be an IL-33 autocrine loop in CNS tumors derived from glial cells, particularly astrocytes (28). TCGA also made it possible to delineate an association between IL-33 mRNA expression and inferior survival in glioblastoma patients (Fig. 2E), suggesting that the IL-33-expressing phenotype defines a glioma subset with a more aggressive course and a worse prognosis.

Angiogenesis is another hallmark of glioblastoma. Notably, Choi et al demonstrated that IL-33 promotes angiogenesis and vasopermeability in vivo and in vitro (47). Endothelial cells are a source of IL-33 and also express the heterodimeric IL1RL1 (27). In the present study, IL-33 was not expressed in all endothelial cells of normal brain and intra-/peritumoral glioma vessels, but this could not be addressed systematically since vessels were not captured on all TMA cores, and the TMA was designed to study tumor tissues. The TMA-based approach allowed for large-scale analysis of multiple human glioma cases. However, the approach is by nature limited to the study of IL-33 expression in the tumor area selected on the TMA. Therefore, a systematic evaluation of different tumor subregions (e.g., necrotic or vascular areas) was not possible.

The present study data suggested that IL-33 may play a role in human glioma development, growth and progression. This could be due to IL-33-mediated communication between glioma cells and components of the tumor microenvironment, such as resident astrocytes, microglia and inflammatory or endothelial cells. Alternatively, IL-33 overexpression in glioma could be a bystander effect reflecting a more general disease-associated phenomenon, as IL-33 is upregulated in other neurological conditions as well (48). The complex interactive network of IL-33 and the extent to which the IL-33/IL1RL1/IL1RAcP axis can be affected by therapeutic intervention will require elucidation in human glioma.

\section{Acknowledgements}

The authors thank Melanie Sachs (Institute of Pathology Liestal, Cantonal Hospital Baselland, Liestal, Switzerland) and Martina Storz (Department of Pathology, Institute of Surgical Pathology, University Hospital Zurich, Zürich, Switzerland) for their expert technical assistance. This study was supported by a grant from Oncosuisse (no. KLS 3110-02-2013) and by a Filling-the-Gap personal grant from the University of Zurich.

\section{References}

1. Gramatzki D, Dehler S, Rushing EJ, Zaugg K, Hofer S, Yonekawa Y, Bertalanffy H, Valavanis A, Korol D, Rohrmann S, et al: Glioblastoma in the Canton of Zurich, Switzerland revisited: 2005 to 2009. Cancer: Apr 18, 2016 (Epub ahead of print).

2. Stupp R, Mason WP, van den Bent MJ, Weller M, Fisher B, Taphoorn MJ, Belanger K, Brandes AA, Marosi C, Bogdahn U, et al: Radiotherapy plus concomitant and adjuvant temozolomide for glioblastoma. N Engl J Med 352: 987-996, 2005.

3. Weller M, van den Bent M, Hopkins K, Tonn JC, Stupp R, Falini A, Cohen-Jonathan-Moyal E, Frappaz D, Henriksson R, Balana C, et al: EANO guideline for the diagnosis and treatment of anaplastic gliomas and glioblastoma. Lancet Oncol 15: e395-e 403, 2014

4. Huse JT and Holland EC: Targeting brain cancer: Advances in the molecular pathology of malignant glioma and medulloblastoma. Nat Rev Cancer 10: 319-331, 2010. 
5. Charles NA, Holland EC, Gilbertson R, Glass R and Kettenmann H: The brain tumor microenvironment. Glia 59: 1169-1180, 2011.

6. Lin Y, Zhang G, Zhang J, Gao G, Li M, Chen Y, Wang J, Li G, Song SW, Qiu X, et al: A panel of four cytokines predicts the prognosis of patients with malignant gliomas. J Neurooncol 114: 199-208, 2013

7. Prosniak M, Harshyne LA, Andrews DW, Kenyon LC, Bedelbaeva K, Apanasovich TV, Heber-Katz E, Curtis MT, Cotzia P and Hooper DC: Glioma grade is associated with the accumulation and activity of cells bearing M2 monocyte markers. Clin Cancer Res 19: 3776-3786, 2013.

8. Yeung YT, McDonald KL, Grewal T and Munoz L: Interleukins in glioblastoma pathophysiology: Implications for therapy. Br J Pharmacol 168: 591-606, 2013.

9. Zhu VF, Yang J, Lebrun DG and Li M: Understanding the role of cytokines in glioblastoma multiforme pathogenesis. Cancer Lett 316: 139-150, 2012

10. Schiering C, Krausgruber T, Chomka A, Fröhlich A, Adelmann K, Wohlfert EA, Pott J, Griseri T, Bollrath J, Hegazy AN, et al: The alarmin IL-33 promotes regulatory T-cell function in the intestine. Nature 513: 564-568, 2014.

11. Beltrán CJ, Núñez LE, Díaz-Jiménez D, Farfan N, Candia E, Heine C, López F, González MJ, Quera R and Hermoso MA: Characterization of the novel ST2/IL-33 system in patients with inflammatory bowel disease. Inflamm Bowel Dis 16: 1097-1107, 2010.

12. Palmer $\mathrm{G}$ and Gabay $\mathrm{C}$ : Interleukin-33 biology with potential insights into human diseases. Nat Rev Rheumatol 7: 321-329, 2011.

13. Préfontaine D, Nadigel J, Chouiali F, Audusseau S, Semlali A, Chakir J, Martin JG and Hamid Q: Increased IL-33 expression by epithelial cells in bronchial asthma. J Allergy Clin Immunol 125: 752-754, 2010

14. Byers DE, Alexander-Brett J, Patel AC, Agapov E, Dang-Vu G, Jin X, Wu K, You Y, Alevy Y, Girard JP, et al: Long-term IL-33-producing epithelial progenitor cells in chronic obstructive lung disease. J Clin Invest 123: 3967-3982, 2013.

15. Kempf W, Zollinger T, Sachs M, Ullmer E, Cathomas G, Dirnhofer S and Mertz KD: Granulomas are a source of interleukin-33 expression in pulmonary and extrapulmonary sarcoidosis. Hum Pathol 45: 2202-2210, 2014.

16. Moulin D, Donzé O, Talabot-Ayer D, Mézin F, Palmer G and Gabay C: Interleukin (IL)-33 induces the release of pro-inflammatory mediators by mast cells. Cytokine 40: 216-225, 2007.

17. Schmitz J, Owyang A, Oldham E, Song Y, Murphy E, McClanahan TK, Zurawski G, Moshrefi M, Qin J, Li X, et al: IL-33, an interleukin-1-like cytokine that signals via the IL-1 receptor-related protein ST2 and induces T helper type 2-associated cytokines. Immunity 23: 479-490, 2005.

18. Chackerian AA, Oldham ER, Murphy EE, Schmitz J, Pflanz S and Kastelein RA: IL-1 receptor accessory protein and ST2 comprise the IL-33 receptor complex. J Immunol 179: 2551-2555, 2007.

19. Küchler AM, Pollheimer J, Balogh J, Sponheim J, Manley L, Sorensen DR, De Angelis PM, Scott H and Haraldsen G: Nuclear interleukin-33 is generally expressed in resting endothelium but rapidly lost upon angiogenic or proinflammatory activation. Am J Pathol 173: 1229-1242, 2008

20. Moussion C, Ortega N and Girard JP: The IL-1-like cytokine IL-33 is constitutively expressed in the nucleus of endothelial cells and epithelial cells in vivo: A novel 'alarmin'? PLoS One 3 : e3331, 2008

21. Carriere V, Roussel L, Ortega N, Lacorre DA, Americh L, Aguilar L, Bouche G and Girard JP: IL-33, the IL-1-like cytokine ligand for ST2 receptor, is a chromatin-associated nuclear factor in vivo. Proc Natl Acad Sci USA 104: 282-287, 2007.

22. Alves-Filho JC, Sônego F, Souto FO, Freitas A, Verri WA Jr, Auxiliadora-Martins M, Basile-Filho A, McKenzie AN, Xu D, Cunha FQ and Liew FY: Interleukin-33 attenuates sepsis by enhancing neutrophil influx to the site of infection. Nat Med 16: 708-712, 2010

23. Haraldsen G, Balogh J, Pollheimer J, Sponheim J and Küchler AM: Interleukin-33-cytokine of dual function or nove alarmin? Trends Immunol 30: 227-233, 2009.

24. Roussel L, Erard M, Cayrol C and Girard JP: Molecular mimicry between IL-33 and KSHV for attachment to chromatin through the H2A-H2B acidic pocket. EMBO Rep 9: 1006-1012, 2008.

25. Xiong Z, Thangavel R, Kempuraj D, Yang E, Zaheer S and Zaheer A: Alzheimer's disease: Evidence for the expression of interleukin-33 and its receptor ST2 in the brain. J Alzheimers Dis 40: 297-308, 2014.
26. Christophi GP, Gruber RC, Panos M, Christophi RL, Jubelt B and Massa PT: Interleukin-33 upregulation in peripheral leukocytes and CNS of multiple sclerosis patients. Clin Immunol 142: 308-319, 2012.

27. Yasuoka S, Kawanokuchi J, Parajuli B, Jin S, Doi Y, Noda M, Sonobe Y, Takeuchi H, Mizuno T and Suzumura A: Production and functions of IL-33 in the central nervous system. Brain Res 1385: 8-17, 2011

28. Hudson CA, Christophi GP, Gruber RC, Wilmore JR, Lawrence DA and Massa PT: Induction of IL-33 expression and activity in central nervous system glia. J Leukoc Biol 84: 631-643, 2008

29. Han P, Mi WL and Wang YQ: Research progress on interleukin-33 and its roles in the central nervous system. Neurosci Bull 27: 351-357, 2011

30. Kempuraj D, Khan MM, Thangavel R, Xiong Z, Yang E and Zaheer A: Glia maturation factor induces interleukin-33 release from astrocytes: Implications for neurodegenerative diseases. J Neuroimmune Pharmacol 8: 643-650, 2013.

31. Sun P, Ben Q, Tu S, Dong W, Qi X and Wu Y: Serum interleukin-33 levels in patients with gastric cancer. Dig Dis Sci 56: 3596-3601, 2011

32. Bergis D, Kassis V, Ranglack A, Koeberle V, Piiper A, Kronenberger B, Zeuzem S, Waidmann $\mathrm{O}$ and Radeke HH: High serum levels of the interleukin-33 receptor soluble ST2 as a negative prognostic factor in hepatocellular carcinoma. Transl Oncol 6: 311-318, 2013

33. Hu LA, Fu Y, Zhang DN and Zhang J: Serum IL-33 as a diagnostic and prognostic marker in non-small cell lung cancer. Asian Pac J Cancer Prev 14: 2563-2566, 2013.

34. Fang KM, Yang CS, Lin TC, Chan TC and Tzeng SF: Induced interleukin-33 expression enhances the tumorigenic activity of rat glioma cells. Neuro Oncol 16: 552-566, 2014.

35. Louis DN, Ohgaki H, Wiestler B and Cavenee WK (eds): WHO Classification of Tumours of the Central Nervous System. IARC Press, Lyon, 2007.

36. Cancer Genome Atlas Research Network: Comprehensive genomic characterization defines human glioblastoma genes and core pathways. Nature 455: 1061-1068, 2008.

37. Gravendeel LA, Kouwenhoven MC, Gevaert O, de Rooi JJ, Stubbs AP, Duijm JE, Daemen A, Bleeker FE, Bralten LB, Kloosterhof NK, et al: Intrinsic gene expression profiles of gliomas are a better predictor of survival than histology. Cancer Res 69: 9065-9072, 2009.

38. Singhal G, Jaehne EJ, Corrigan F, Toben C and Baune BT: Inflammasomes in neuroinflammation and changes in brain function: A focused review. Front Neurosci 8: 315, 2014

39. Jovanovic IP, Pejnovic NN, Radosavljevic GD, Arsenijevic NN and Lukic ML: IL-33/ST2 ax is in innate and acquired immunity to tumors. Oncoimmunology 1: 229-231, 2012.

40. Villarreal DO, Wise MC, Walters JN, Reuschel EL, Choi MJ, Obeng-Adjei N, Yan J, Morrow MP and Weiner DB: Alarmin IL-33 acts as an immunoadjuvant to enhance antigen-specific tumor immunity. Cancer Res 74: 1789-1800, 2014.

41. Gao K, Li X, Zhang L, Bai L, Dong W, Gao K, Shi G, Xia X, Wu L and Zhang L: Transgenic expression of IL-33 activates CD8(+) T cells and NK cells and inhibits tumor growth and metastasis in mice. Cancer Lett 335: 463-471, 2013.

42. Curran CS and Bertics PJ: Eosinophils in glioblastoma biology. J Neuroinflammation 9: 11, 2012

43. Hussain SF, Yang D, Suki D, Aldape K, Grimm E and Heimberger AB: The role of human glioma-infiltrating microglia/macrophages in mediating antitumor immune responses. Neuro Oncol 8: 261-279, 2006.

44. Dong H, Zhang X and Qian Y: Mast cells and neuroinflammation. Med Sci Monit Basic Res 20: 200-206, 2014.

45. Skaper SD, Facci L and Giusti P: Mast cells, glia and neuroinflammation: Partners in crime? Immunology 141: 314-327, 2014.

46. Merk BC, Owens JL, Lopes MB, Silva CM and Hussaini IM: STAT6 expression in glioblastoma promotes invasive growth. BMC Cancer 11: 184, 2011

47. Choi YS, Choi HJ, Min JK, Pyun BJ, Maeng YS, Park H, Kim J, Kim YM and Kwon YG: Interleukin-33 induces angiogenesis and vascular permeability through ST2/TRAF6-mediated endothelial nitric oxide production. Blood 114: 3117-3126, 2009.

48. Gadani SP, Walsh JT, Smirnov I, Zheng J and Kipnis J: The glia-derived alarmin IL-33 orchestrates the immune response and promotes recovery following CNS injury. Neuron 85: 703-709, 2015 